\title{
La supuesta revuelta mudéjar preconizada por el zabazala de Deza (Ágreda, 1339)
}

\section{The supposed Mudejar revolt praised by the Muslim director of prayer from Deza (Ágreda, 1339)}

\author{
Pedro Andrés PorRas ARBOLEDAS \\ Universidad Complutense de Madrid \\ pporras@der.ucm.es
}

Recibido: 15 de septiembre de 2014

Aceptado: 12 de junio de 2015

\section{RESUMEN}

En los prolegómenos de la batalla del Estrecho entre benimerines y granadinos, por un lado, y Alfonso XI de Castilla, por otro, el zabazala de Deza, de acuerdo con una denuncia producida en Ágreda, intentó sublevar sin éxito a las comunidades mudéjares de la frontera castellana con Aragón y Navarra.

Palabras clave: Batalla del Estrecho, revuelta mudéjar, Alfonso XI de Castilla, benimerines, nazaríes, zabazala, Deza y Ágreda.

\begin{abstract}
In the prefaces of the battle of the Strait of Gibraltar between Marinids and Nasrids from Africa and Granada, on the one hand, and Alfonso XI of Castile, for other one, the zabazala of Deza, according with a denunciation produced in Ágreda, tried to revolt without success to the Muslim communities of the Castilian border with Aragon and Navarre.
\end{abstract}

Keywords: Battle of the Strait of Gibraltar, Mudejar revolt, Alfonso XI of Castile, Marinids, Nasrids, zabazala (Muslim director of the prayer), Deza and Ágreda. 
Se atribuye a Manuel Azaña la sentencia «en España, si quieres guardar un secreto, escríbelo en un libro»; ignoro si en la actualidad los índices de lectura son más altos entre los españoles que en los tiempos de la República. Supongo que sí, aunque sólo sea por mor de la alfabetización de la mayoría de la ciudadanía, ahora bien, tengo para mí que, en el ámbito universitario, la máxima del ex-presidente republicano sigue teniendo su predicamento. Precisamente hoy en que contamos con repertorios bibliográficos online, a los que acudir cómodamente desde cualquier terminal; hoy, cuando más fácil resulta editar libros y revistas, habiéndose llegado a decir que estamos en la sociedad de la información, es curioso que hoy se siga practicando lo que yo no dudaría en calificar de filibusterismo bibliográfico. Me refiero con ello a la práctica bastante extendida de citar en los trabajos científicos tan sólo a los amigos o a aquellos a quienes se quiere favorecer, con olvido ostensible del resto de la profesión, a la que ni se lee ni se cita. Desde luego, cada autor es muy libre de citar en sus trabajos a quien mejor le parezca, sin embargo, cuando se dejan de mencionar obras básicas o aquellas que contradicen lo que se está defendiendo por el filibustero, uno no puede dejar de pensar si algo tendrá que ver en esto el endiablado sistema actual de valoración de citas, usado por las agencias de evaluación y acreditación. ${ }^{1}$

Los documentos que voy a mencionar aquí llevan ya un tiempo editados o regestados, pero, como no deseo que caiga sobre ellos la amenaza del olvido anunciada por Azaña, voy a resaltarlos en un trabajo concreto con un título, espero que, llamativo. Me refiero a un hecho del que no creo que se conserve ninguna otra mención en las fuentes: la rebelión orquestada por las comunidades mudéjares de la frontera castellana con Aragón y Navarra durante los prolegómenos de la batalla del Estrecho, ${ }^{2}$ azuzada por las revelaciones esotéricas del zabazala -o director de la oración en la mezquita- de Deza. ${ }^{3}$

De acuerdo con el documento que vuelvo a recoger en apéndice ahora (documento 1), aunque los hechos se remontaban a fines de abril de 1339, su existencia no llegó

${ }^{1}$ Sea como fuere y hablando de lo que aquí nos interesa, no quería dejar pasar la ocasión de editarse un volumen de Anaquel en homenaje a su fundadora, la profesora Viguera Molins, buena amiga y profesional admirable, para tomar parte en el mismo, siquiera fuera con un breve trabajo, como éste que presento.

${ }^{2}$ Se conoce como batalla del Estrecho, como cualquier historiador sabe, a la encarnizada lucha librada a fines de la primera mitad del siglo XIV por Alfonso XI de Castilla contra los benimerines y sus aliados nazaríes a fin de taponar el estrecho de Gibraltar a los refuerzos que desde África pasaban los musulmanes a la Península Ibérica, y que concluyó con la victoria castellana.

El papel que Ágreda y las otras aljamas musulmanas de su entorno, en caso de invasión generalizada, hubiera sido muy importante, por suponer la llave que abría Navarra y Aragón desde esa zona de Castilla.

${ }^{3}$ Los escritos de denuncia presentados ante las autoridades de Ágreda en Pedro Andrés PORRAS ARBOLEDAS, «Colección diplomática de Ágreda. Regestas reales (1211-1520)», Cuadernos de Historia del Derecho, 19 (2012) 419-420 (Doi: http://dx.doi.org/10.5209/rev_CUHD.2012.v19.43146), y las medidas regias tomadas al respecto en pp. 306-307. En la Colección diplomática sólo se transcribe completo el documento de la denuncia de Adamelque; el resto sólo están regestados.

En la nota 4 de dicho trabajo puede encontrarse un completo estado de la cuestión de la bibliografía existente sobre la historia de Ágreda y su aljama. 
a conocimiento de la justicia castellana hasta cuatro meses más tarde. En efecto, el miércoles, 25 de agosto Juan López, escribano público, hijo de Gil López, arcipreste de Calatañazor y vicario de Ágreda, presentó ante Miguel Pérez, juez de esta villa, Garci Sánchez y Gil Pérez, alcaldes de fuero, y Martín Ruiz y Ruy Martínez, jurados del rey en Ágreda, un escrito de denuncia.

El texto de la misma fue hecho público ante Blasco Martínez, escribano público de Ágreda, en presencia de una serie de testigos, por Juan López, que se dirigió al mismo juez, a los alcaldes citados y a otros tres (Gonzalo de Vera, Martín González y Garci Jiménez) y a tres jurados reales (los dos conocidos y Gonzalo Martínez). Exponía cómo el domingo, 6 de junio, estando en su domicilio, acudió allí Adamelque, hijo de Mahoma, alguacil de la morería de la villa, para darle cuenta de que el miércoles 25 de abril se había celebrado contubernio dentro de la morería, habiendo tomado parte en la reunión Esmay de Axa Cidiello, Alí Alfaquí, Yuce de Muza, Mahoma del Romo, Ayn, hijo de Mahoma de Ayn, Zuleima de Sancho, Esmay, hijo de Zalema de Ayn, Adamelque, hijo de Zah, Farache de Adalid, Mahoma Pelayo, Esmay, hijo de Yuce Audella Monijo, Mahoma de Farache el Tremenzojo, Yuce Almorani y otros más innominados. Allí se leyó una carta que les había remitido el zabazala de Deza con Audella Yuce, hijo del alguacil de esa morería:

en la qual disíe que les fesíe saber que los moros de allén mar que pasavan contra Castiella e contra Aragón e que él fallava en los signos de las estrellas que los moros avian a vencer e christianos de seer vencidos.

Et que se apercibiesen de armas e de viandas, e que se fortaleciesen porque ellos fincasen con el logar e se pudiesen defender en él.

E esto que lo fisiesen saber al aljama de Aguilar e lo fablasen con ellos, porque todos toviesen a una, que mucho encerta verien lo que los moros cobdiciavan.

Desde luego, los mudéjares de Ágreda no se tomaron la predicción e instrucciones del iluminado clérigo a humo de pajas, ya que lo pusieron en obra de inmediato. Lo primero fue hablar ese mismo miércoles con Mahoma de Yuce y Mahoma zapatero, moros de la aljama de Aguilar de Río Alhama - concejo que acababa de integrarse en 1335 como aldea de Ágreda-, para hacerles partícipes de sus intenciones subversivas. No contentos con ello, esa misma noche se hizo una nueva reunión clandestina en la mezquita de Valladar, en el seno de la aljama, juntándose los arriba mencionados, sin los dos de Aguilar, y con algunos más, entre ellos Huda, hija de Mahoma de Gali. Allí decidieron anunciar la buena nueva a las demás aljamas mudéjares de la comarca. Además, resolvieron poner tres velas y cuatro rondas en la morería y fortaleza contra la parte de la villa, poblada por cristianos y hebreos. También acordaron cerrar todas las puertas de la morería y poner guardas en ellas, excepto en los postigos que ya estaban cerrados. 
Sin pérdida de tiempo, el sábado siguiente comenzaron a abastecer y fortificar el barrio, metiendo provisiones y taponando con tapias los adarves, lo que no se había hecho en los últimos 60 años.

Aunque probablemente las autoridades cristianas eran ajenas a todos estos preparativos e intenciones, los musulmanes estaban en actividad febril y atentos a cualquier eventualidad, de hecho, el primero de mayo, miércoles, con ocasión de que varios hombres de la villa habían querido entrar en la morería a hablar con Alfonso Fernández, ballestero del Rey, que estaba en ella, aquellos se pusieron en armas y se reunieron como tropa organizada dentro del castillo (en parada), poniendo efectivos para controlar las torres de la fortaleza, las cámaras de la casa de Mahoma el alguacil y las plazas de la aljama. El denunciante en aquel momento no sabía la razón de aquellos movimientos, salvo ende que creye que lo fasien con entención de se alçar con la dicha morería.

Ocho días más tarde llegó a Ágreda Mahoma alguacil, que había andado fuera, y, sabido lo que se estaba tramando, les mandó por plaça que se fortaleciesen. No olvidaron los mudéjares agredanos los aspectos espirituales, ya que todos los días rezaban y ayunaban para que su Dios les favoreciese. El ayuno, al menos, duró dos días.

Adamelque, sea porque veía la inviabilidad del proyecto, sea porque temía que su padre perdiese el oficio de alguacil de la morería o, simplemente, porque tenía sus lealtades con las autoridades cristianas, decidió dar parte de todos estos hechos al escribano Juan López, el cual fue con él a presentar la denuncia ante los mandatarios cristianos, juez, alcaldes y jurados reales; Juan invitó a todos éstos a que se certificaran de la veracidad de lo denunciado preguntando directamente a Adamelque; éste juró que todo era cierto y que no hacía la denuncia por maldad o malquerencia, sino con verdad y buscando el servicio del Rey.

Fueron testigos de este acto Diego Fernández, hijo de Gil Pérez, Lope Sánchez de Arroyo, Gonzalo Fernández de la Mata, Diego Martínez de San Román, Martín González, hijo de Ruy González, y Farache, hijo de Mahoma Ley Cornago. El documento, redactado por Blasco Martínez, fue notificado el día siguiente, 26 de agosto, al alcalde Gil Pérez de la Vicaría, siendo testigos dos cristianos y Zalema, hijo de Audella de Mahoma Jamila.

Al tiempo que Juan López presentó su escrito hizo lo propio Sancho Sánchez de Miranda, a la sazón alcaide del castillo de la morería, donde relataba de nuevo los hechos descritos en la denuncia anterior, a los que calificaba de traición, de ser ciertos, si bien el único mudéjar que aparecía citado era Adamelque. Miranda se pronunció contra las acusaciones vertidas por éste y solicitó que fuera puesto en prisión hasta que el Rey averiguase lo sucedido (documento 2). Aprovechó la ocasión para quejarse ante los alcaldes de que se hubiese prendido a parte de sus protegidos, citando en concreto a Mahoma el alguacil, Ayn, hijo de Mahoma de Ayn, y Zulema de Sancho, ya que eso le agraviaba, pues caían bajo su jurisdicción. La justicia le respondió que era causa de gravedad que atañía al servicio real (documento 3 ). 
Es evidente que la gravedad de los hechos hizo que las autoridades municipales tomasen cartas en el asunto, prendiendo a los denunciados —en realidad, además de los tres mencionados en el escrito de queja del alcaide estaban presos otros dos: Esmay el Bolsero y Mahoma zapatero-, lo que el alcaide del castillo entendía que era lesivo para sus privilegiadas relaciones con la morería local. En cualquier caso, el asunto pasó adelante hasta llegar a la Corte de Alfonso XI: estando éste en Navamorcuende, a mediados del mes de octubre, remitió dos documentos a las autoridades de Ágreda; en la primera hacía constar que los moros de Ágreda se habían quejado ante él de que habían sido prendidos algunos de ellos, por ello se recelaban de que sus vecinos cristianos, aprovechando la ocasión, les causarían daño en sus personas o les robarían sus bienes. Entendía el monarca que era de importancia saber la verdad de lo sucedido y, en consecuencia, ordenó a la justicia de la villa que no consintiese que se causase daño a nadie hasta tanto la causa fuere fallada por derecho (documento 4).

La carta real fue presentada ante el concejo por Adamel, hijo de don Celim, el último día de octubre, junto con la otra que más abajo glosamos. La respuesta del ayuntamiento fue que la obedecían y cumplían con gusto, es más, prometían tratar a sus vecinos mudéjares con mucha onra e mucho plaser. Además, el juez y los alcaldes ordenaron al portador de la carta que compareciera a la próxima audiencia a presentar los fiadores de los encausados, así ellos les asignarían plazo para comparecer a presencia del monarca, como mandaba la carta regia. Fueron testigos de esto tres cristianos y Farache, hijo de Adalid, uno de los primeramente acusados.

En la segunda de las cartas reales, de un día posterior a la ya mencionada, comunicaba el Rey a la justicia de la villa que había sabido que por denuncia de Adamel, hijo de Mahoma el alguacil, estaban presos Mahoma, hijo de don Hamet, Esmay el Bolsero, Aya, hijo de Mahoma de Aya, Zuleima, hijo de Sancho, Mahoma zapatero y el mismo Adamel. Como deseaba saber lo ocurrido, don Alfonso les ordenó que todos ellos presentasen fiadores, por valor de 20.000 maravedíes cada uno, que garantizasen que en quince días se presentarían en la Corte, sin contar los plazos de nueve días de Corte y los tres del pregón; el que no tuviera garantes, debería ser enviado preso y a buen recaudo ante su presencia, a su propia costa.

Este documento fue presentado por segunda vez por el mismo Adamel, hijo de don Celim, el martes, 3 de noviembre, pidiendo a la justicia que recibiera fiadores. Sorprendentemente, teniendo en cuenta la gravedad de los hechos denunciados, fueron doce los vecinos cristianos de la villa que se obligaron solidariamente a pagar $20.000 \mathrm{mrs}$. al Rey — cantidad ciertamente importante - para el caso de que alguno de los reos no compareciese a plazo ante el tribunal real. El juez y los alcaldes recibieron las fianzas y les ordenaron a los encartados estar presentes ante el monarca antes de la finalización del plazo. ${ }^{4}$ El que no compareciese sería tenido por culpable

${ }^{4}$ Terminada de leer la carta, Adamel (o Adamelque, esto es, Abd el Malik), hijo de don Celim, y don Alí Alfaquí pidieron a los oficiales que procedieran a recibir a sus fiadores; don Mahoma Algua- 
de los hechos de que se les acusaba. Fueron testigos dos escribanos y dos andadores, todos cristianos, además de Mahoma, hijo de Alí.

Así pues, el 3 de noviembre los cinco encartados ya estaban en libertad y prestos para salir de inmediato para la Corte, al haber sido avalados por buen número de sus vecinos cristianos; no puede decirse lo mismo del acusador, al que se tachaba de haber presentado una denuncia falsa. Éste no consiguió que nadie le afianzase, de modo que hubo de ser conducido preso a la Corte a su costa. Las actas municipales conservan los trámites que se produjeron entre los días 5 y 7 del mismo mes.

El primero de esos días tres de los cinco alcaldes de fuero solicitaron al juez, a cuyo cargo estaba el reo, que le llevase a su presencia a fin de que declarase quiénes eran sus fiadores y asignarle, acto seguido, plazo para presentarse ante el tribunal regio. El hijo del alguacil mudéjar respondió a la justicia que no disponía de avalistas, de modo que le remitiesen a la Corte, no sin antes recusar a Martín González alcalde. Los tres alcaldes decidieron platicar entre ellos el modo de enviar al rey a Adamelque (documento 5).

Finalizada la audiencia, el reo fue devuelto al juez, que de nuevo se hizo cargo del mismo (documento 6). A continuación el juez y dos de los alcaldes convocaron a la reunión en que debían decidir quién llevaría al preso a la Corte al quinto alcalde, Gonzalo de Vera; éste, probablemente temiéndose que eso significase que el encargo recaería en su persona, se negó a reunirse con ellos, alegando que la carta real no rezaba con él, pues no había tomado parte en ninguna de las actuaciones del caso, lo que era cierto. Los otros oficiales le respondieron que sí que le concernía el mandato real $\mathrm{y}$, a pesar de que le amenazaron con cobrarle daños y perjuicios, no consiguieron que torciera su voluntad (documento 7).

Finalmente, en el concejo abierto que se celebró el domingo día 7 el juez y dos de los alcaldes encomendaron a Garci Sánchez alcalde la tarea de llevar al preso ante el monarca; Garci no tuvo problema en aceptar el encargo (documento 8).

Desconocemos el desenlace de este turbio y descabellado asunto.

Con los escasos datos conservados es difícil pronunciarse sobre la veracidad de la denuncia presentada por Abd el Malik, hijo del alguacil de la aljama mudéjar de Ágreda, contra numerosos de sus vecinos. Por un lado, abona a favor de la credibilidad de la acusación la profusión y minuciosidad de datos denunciados, así como la

cil, hijo de don Hamete, Esmaín el Bolsero, Ayn, hijo de Mahoma de Ayn, Zuleima de Sancho y Mahoma zapatero dieron por tales a Juan Garcés de los Fayos, Pedro Vera, hijo de Fernando Zapata, Ruy Fernández, hijo de don Fernando, Valer Garcés, hijo de Fernando Martínez de la Mata, Garci Fernández, hijo de don Fernando, Gonzalo Martínez, hijo de don Gil Pérez, ex-arcipreste de Ágreda, Garci Jiménez, hijo del dicho Juan González, Juan González, hijo Juan González, Rodrigo Alfonso, hijo de Alfonso Fernández de Quintana, Gonzalo Pérez, hijo de Domingo Martínez, Juan Garcés, hijo de Fernando García, y Pedro Jiménez, hijo de Nicolás el zapatero, vecinos de Ágreda. Todos ellos obligaron sus bienes muebles y raíces, doquiera que estuvieran, pero no sus personas, lo que venía siendo habitual por entonces.

Por falta de conocimiento de la lengua árabe renuncio a intentar inferir los nombres de los mudéjares aquí citados; si lo he hecho con este Abd el Malik es por resultar evidente la relación. 
realidad del enfrentamiento militar con los musulmanes de Granada y África; sin embargo, por otro, opera en sentido contrario el que denunciara a su propio padre y que la sociedad cristiana de la villa avalara con sus fianzas a los denunciados y no al denunciante. Si los hechos denunciados eran ciertos - hipótesis que creo más plausible-, es evidente que los agredanos, vista la inanidad efectiva de los propósitos de los musulmanes, prefirieron echar tierra sobre el asunto por bien de la convivencia diaria entre las tres comunidades confesionales.

\section{APÉNDICE}

\section{DOCUMENTO 1}

\section{9/08/25 (miércoles). [Ágreda]}

Denuncia presentada por Adamelque, hijo de Mahoma Alguacil, por los hechos acaecidos en la morería cuando sus habitantes se pusieron en armas; formaliza la denuncia ante la justicia el escribano Juan López, al que se habia dirigido Adamelque.

Archivo Histórico Municipal de Agreda, Protocolos Nuevos, nº 7, fol. 8v-9v. Entre paréntesis apellidos de lectura dudosa.

Miércoles, .XXV. días de agosto, era de mill e .CCC. e .LXXVII. años, Johán Lopes, escrivano público de Ágreda, mostró e fiso leer un escrito a Miguel Peres, jués de Ágreda, a Garci Sanches, Gil Peres e Martín Gonçales, alcaldes, e a Martín Roys y Roy Martines, jurados por el Rey en Ágreda:

En presencia de nos, Blasco Martines, escrivano público de Ágreda, e de los testigos que aquí son escriptos, yo Johán Lopes, escrivano público de Ágreda, fijo de Lope Gil, arcipreste de Calatannaçor, vicario del dicho logar, fago saber a Miguel Peres, jués de Ágreda, e a Garci Sanches e a Gil Peres e a Gonçalo de Vera e a Martín Gonçales e a García Xemenes, alcaldes, e a Martín Roys e a Gonçalo Martines e a Roy Martines, jurados, que domingo, seys días andados del mes de junio, de la era de mill e .CCCLXXVII. annos, seyendo en mi casa, vino y Adamelque, fijo de Mahoma, el alguasil moro de la dicha morería, et dixo que él estando en la dicha morería el postrimero miércoles [25] del mes de abril que agora pasó de la dicha era, que Esmay de Axa Cidiello e Alí Alfaquí e Yuce de Muça e Mahoma del Romo e Ayn, fijo de Mahoma d'Ayn, e Çuleyma de Sancho e Esmay, fijo de Çalema de Ayn, e Adamelque, fijo de Çah, e Farache d'Adalit e Mahoma Pelayo e Esmay, fijo de Yuce Audella Monijo, e Mahoma de Farache el Tremençoio e Yuce Almorani e otros moros de la dicha morería con ellos, que leyeron una carta que les enbió el çavaçala de Deça, con Audella Yuce, fijo del alguasil de Deça, en la qual disíe que les fesíe saber que los moros de allén mar que pasavan contra Castiella e contra Aragón e que él fallava en los signos de las estrellas que los moros avían a vencer e christianos de seer vencidos. 
Et que se apercibiesen de armas e de viandas, e que se fortaleciesen porque ellos fincasen con el logar e se pudiesen defender en él.

Et esto que los fisiesen saber al aljama de Aguilar e lo fablasen con ellos, porque todos toviesen a una, que mucho encerta veríen lo que los moros cobdiciavan.

Et otrosí, que este miércoles que los sobredichos que fablaron este pleyto mismo con Mahoma de Yuce e con Mahoma çapatero, moros d'Aguilar.

Et que luego este dicho día en la noche que se ayuntaron en la mesquita de Valladar, en la dicha morería, todos los sobredichos, salvo ende los dos moros de Aguilar, e otros más moros con ellos de la dicha morería, e que eran y con ellos Huda, fija de Mahoma de Gali, e que lo enbiaron desir esto a parada de las aljamas de las comarcas desta tierra.

Et que ordenaron luego que velasen contra la villa de Ágreda tres velas e quatro rondas.

Et otrosí, que fisiesen cerrar las puertas de la dicha morería e que pusiesen y porteros que las guardasen e salvo ende los postigos que non tenían abiertos.

Et otrosí, el sábado luego siguiente que començaron a fortalecerse e a poner mucha vianda en la dicha morería et a tapar en los adarves de la dicha morería, do non se avíe echado tapia de sesenta annos acá.

Et otrosí, que el miércoles primero de mayo, por rasón que entravan algunos omes ese día de la villa a la morería a veer a Alfonso Ferrandes, ballestero de nuestro sennor el Rey, que estava y, qu'estos sobredichos moros e otros con ellos de la dicha morería que se armaran e se pusieran parada dellos en el castiello de la dicha morería e en las torres dende e otros en las cámaras de las casas de Mahoma el alguasil e otros en las encrusejadas de las plasas de la dicha morería, e la rasón por que lo fasíen, que no lo sabíe, salvo ende que creye que lo fasíen con entención de se alçar con la dicha morería.

Et otrosí, que a cabo de ocho días que vino el dicho Mahoma alguasil que se non avíe acercado y, qu'era fuera de la villa, e que sopo todo este fecho e que les mandó por plaça que se fortaleciesen.

Et otrosí, que fasíen de cada día oración porque Dios ayudase a los moros e que an ayunado por esta rasón dos días.

Et yo, así como natural e vasallo de mi sennor el Rey, queriendo su servicio e entendiendo que si estas cosas así fuesen, que seríe muy grant deservicio suyo, e digo geles e requieroles que, pues el dicho Adimelque está presente ante ellos, quel fagan desir si lo dixo a mí así como yo digo, porque el Rey sea servido, e de todo esto que digo e del conoscimiento que el dicho Adimelque fiso ante ellos e ante nos el dicho escrivano, pido vos que me dedes testimonio signado con vuestro signo, porque lo yo pueda mostrar do deva e a mí cunpla.

Et los dichos oficiales dixieron que, pues el dicho Adamelque está presente, que'l preguntavan que esta rasón que les dixo Johán Lopes si la avíe dicho él, e el dicho Adamelque dixo que sí e así como lo avíe dicho al dicho Johán Lopes que así lo disíe, e lo denunciava a los dichos oficiales, segunt está escripta de suso en este 
escripto. E tomaron jura al dicho Adamelque que todas estas rasones e denunciación que non se movíe [nin] fasía dicha denunciación maliciosamente, nin por malquerencia, salvo verdaderamente, guardando servicio del Rey, e jurolo así.

Testigos, Diago Ferrandes, fijo de Gil Peres, e Lope Sanches de [Arroyo], e Gonçalo Ferrandes de la Mata, e Diago Martinea de Sant Román, e Martín Gonçales, fijo de Roy Gonçales, e Farache, fijo de Mahoma [Ley Cornago].

E yo, Blasco Martines, escrivano público de Ágreda, fuy presente con los dichos oficiales en esto que dicho es e lo escreví e este signo fis.

Este denunciamiento leyeron a Gil Peres de la Vicaría, alcalde, jueves .XXVI. días de agosto de la dicha era.

Testigos, Alfonso Peres, fijo de Miguel Peres, Diago Martines de Rosa y Çalema, fijo de Abdella de Mahoma Jamila.

\section{DOCUMENTO 2}

\section{9/08/25 (miércoles). [Ágreda]}

Sancho Sánchez de Miranda, alcaide del castillo de la morería de Ágreda, tras relatar los hechos contenidos en la denuncia de Adamelque - a los que califica de traición, de ser ciertos-, sin mencionar a ningún implicado, solicita a la justicia que prenda al denunciante.

AHMA, Protocolos Nuevos, $n^{\circ}$ 7, fol. 9v.

Ante Martín Gonçales e García Sanches alcaldes e Miguel Peres jués e Roy Martines e Martín Roys, jurados de Ágreda, en presencia de mí, Blasco Martines, escrivano público de Ágreda, e de los testigos que en fin deste testimonio son escriptos, pareció y Sancho Sanches de Miranda, alcayde del castiello de la morería de Ágreda, e dixo que'l fisieren emienda que Adamelque moro, que es natural de la dicha morería e fijo de Mahoma el alguasil, que andava públicamente disiendo por la dicha villa de Ágreda a muchos omes que algunos moros del aljama de la dicha morería que ovieron una carta del çavaçala de Deça el postrimer miércoles de abril que agora pasó, en que disíe que les fasíe saber que los moros de allén mar que pasavan contra Castiella e contra Aragón e que él que fallava en los signos de las estrellas que los moros que avíen de vencer e christianos de seer vencidos, e que se apercibiesen de armas e de viandas e que se fortaleciesen, porqu'ellos pudiesen fincar con el logar que teníen, e que lo fisiesen saber al aljama de Aguilar e lo fablasen con ellos, que mucho encera veríen lo que los moros cobdiciavan. Et que este mismo día en la noche que se avíen ayuntado en la mesquita de la dicha morería algunos moros de la dicha morería e que lo enbiaran desir esto a parada de las aljamas de las comarcas desta tierra. Et que ordenaron luego que velasen tres velas 
e .IIII. roldas escontra la dicha villa de Ágreda e que fisieron cerrar las puertas de la dicha morería e que pusiesen y porteros que las guardasen, salvo ende los postigos que tenían abiertos. E que luego el sábado siguiente que començaron a fortalecerse e a tapiar en los adarves de la dicha morería, do no se avíe echado tapia gran tienpo avíe pasado, e que luego el miércoles adelante segunt que entravan algunos omes de la villa a la dicha morería a ver Alfonso Rodrigues, vallestero de nuestro sennor el Rey, que algunos moros de la dicha morería que se armaran e se pusieran parada dellos en algunas fortalesas de la dicha morería. E esto que lo fizieran con condición de se alçar con la dicha morería. Et otras cosas muy malas e feas, las quales, si así son verdat, son contra el sennorío de nuestro sennor el Rey e que tannen en caso de trayción.

Por ende, dixo que requeríe que fasíe afruenta en nonbre del Rey, así como alcayde del su castiello, a los dichos oficiales que, pues el dicho Adamelque pareció ante ellos agora, que lo prendan e que pongan tal recaudo en él, non dalde'l suelto ni fiado fasta do el dicho sennor Rey enbíe saber la verdat deste fecho e mande sobrello lo que la su mercet fuere, porque el dicho sennor Rey sea servido, e cosa ninguna non se aparte nin se meta del ome que tales rasones disen que a dicho. Et desta afruenta e requerimiento que les fiso pidió a mí, el dicho escrivano, que'l dé testimonio, porqu'él lo pueda mostrar a nuestro sennor el Rey, como cunplen lo que es su servicio.

E los dichos oficiales dixieron que el dicho Adamelque que non está presente ante ellos e sobresto que avríen su acuerdo e que farán todas las cosas que fueren servicio del Rey.

Testigos, Pasqual Peres del Cacho e García, fijo de Diago Martines.

\section{DOCUMENTO 3}

\section{9/08/25 (miércoles). [Ágreda]}

Sancho Sánchez de Miranda, alcaide del castillo de la morería de Ágreda, se muestra sorprendido de que la justicia hubiera prendido a tres mudéjares sin haberle dado parte, pues a él atañía la jurisdicción de la morería.

AHMA, Protocolos Nuevos, $\mathrm{n}^{\circ}$ 7, fol. 10r.

Ante Miguel Peres, jués de Ágreda, e Gil Peres, alcalde de Ágreda, pareció Sancho Sanches, alcayde del castiello de la morería de Ágreda, dixo que se maravillava por qué ellos avíen prendido a don Mahoma Alguasil e Ayn, fijo de Mahoma d'Ayn, e a Çulema de Sancho, non aviéndole fecho a él ninguna afruenta nin aviéndole fecho requerimiento ninguno porque'l faser, de la qual cosa teníe que le an fecho e le fasen muy grant agravio, pues él el dicho castiello tiene por el dicho sennor Rey. Et que los requiere e afaga afruenta que, si alguna querella les an dado de los dichos 
moros que son presos o de alguno de la dicha aljama, que gela muestren e que gelo digan, que él presto está para faser conplimiento de derecho dellas o de qualquier dellas e qualquier querella aya dellos, quanto más estando él presente quando los prisieron. Et desta afruenta e requerimiento que les fase pidió a mí, el dicho Blasco Martines, escrivano público de Ágreda, que'l diese testimonio por que lo yo pueda mostrar a nuestro sennor el Rey.

E los dichos alcaldes dixeron que los tomaron porque servicio del Rey se cunpla.

Testigos los de suso.

\section{DOCUMENTO 4}

\section{9/10/31 (domingo). [Ágreda]}

Adamel, hijo de don Celim, y don Ali Alfaqui, en nombre de los moros acusados de traición por Adamelque, hijo de Mahoma Alguacil, presentan ante el concejo y sus oficiales sendos mandamientos de Alfonso XI, uno de seguro y otro de emplazamiento y soltura bajo fianzas.

El concejo y oficiales obedecen y cumplen las cartas, y juez y alcaldes, en virtud de la segunda carta, toman fiadores a los cinco denunciados y les asignan plazo para comparecer ante el tribunal real.

AHMA, Protocolos Antiguos, 02/04, fol. 66v-67r. El segundo documento real también en folio $68 \mathrm{v}$, con su cumplimiento.

Domingo, postrimero día de outobre de la dicha era, en presencia de mí, Pero Ximenes, escrivano público de Ágreda, e de los testigos que aquí son escriptos, seyendo en el concejo de Ágreda ayuntados a la puerta de la eglesia de Sant Miguel del dicho logar a concejo pregonado, como la an de uso e de costunbre, e otrosí seyendo y Miguel Peres jués e Martín Gonçales e Garci Ximenes e Garci Sanches e Gil Peres, alcaldes del dicho logar, Ademel, fijo de don Celín, mostró e fiso leer dos cartas de nuestro sennor el Rey, fechas en esta guisa:

\section{[1339/10/16. Navamorcuende]}

«Don Alfonso, por la gracia de Dios, Rey de Castiella, de Toledo, de León, de Ga1lisia, de Sevilla, de Córdova, de Murcia, de Jahén, del Algarbe e sennor de Molina. Al concejo e a los alcaldes e al jués de Ágreda o a qualquier o qualesquier de vos que esta nuestra carta vierdes. Salut e gracia.

Sepades que el aljama de los moros de y de Ágreda se nos enbiaron querellar e disen que por rasón de denunciación que fue fecha a Nos los dichos alcaldes e jués que vos que prendiestes a algunos moros de la dicha aljama. E Nos tenemos por bien de saber en este fecho en cómo pasó. E agora la dicha aljama de los dichos mo- 
ros disen que se recelan que en quanto Nos sabemos en cómo este fecho pasó que algunos que les farán mal e danno e que les tomarán alguna cosa de lo suyo sin rasón e sin derechos, como non deven. E enbiaronnos pedir merced que mandásemos y lo que toviésemos por bien.

Porque vos mandamos, vista esta nuestra carta, que non consintades a ninguno nin a ningunos que fagan mal nin danno a los moros de la dicha aljama sin rasón e sin derecho nin los menasen nin les tomen ninguna cosa de lo suyo por esta rasón fasta que Nos sepamos este fecho en cómo pasó e lo libremos en aquella manera que falláremos por derecho. E non fagades ende al por ninguna manera, son pena de la nuestra merced e de cient mrs. de la moneda nueva a cada uno. E de como vos esta nuestra carta fuere mostrada e cunplierdes, mandamos a qualquier escribano público que para este fuere llamado que dé ende al que vos la mostrare testimonio signado con su signo. E non faga ende al so la dicha pena. E porque entendades que esto es nuestra voluntad, mandamos seellar esta carta con el nuestro seello de la poridat. La carta leyda dátgela. Sada en Navalmorcuende, .XVI. días de oytobre, era de mill e .CCCLXXVII. annos. Yo, Pero Ferrandes de la Cámara, la fis escrevir por mandado del Rey».

\section{[1339/10/17. Navamorcuende]}

«Don Alfonso, por la gracia de Dios, Rey de Castiella, de Toledo, de León, de Gallisia, de Sevilla, de Córdova, de Murcia, de Jahén, del Algarbe e sennor de Molina. $\mathrm{Al}$ concejo e a los alcaldes e al jués de Ágreda. Salut e gracia.

Bien sabedes en cómo nos enbiastes desir que por rasón de denunciación que vos fuera fecha por Adamel, fijo de Mahomat el alguasil, que vos que prendiestes a Mahomat, fijo de don Hamet, e a Esmay el Bolsero e Ayn, fijo de Mahoma d'Ayn, e a Çueleyma, fijo de Sancho, e a Mahoma çapatero e al dicho Adamel, el que vos fisiera la dicha denunciación, e que los teníedes presos. E agora Nos tenemos por bien de faser saber la verdat deste fecho en cómo pasó. E entre tanto que vos de los dichos moros [havés] fiadores fasta en quantía de .XX. mill mrs. a cada uno dellos que parescan en la nuestra Corte personalmente ante Nos sobresta rasón.

Porque vos mandamos, vista esta nuestra carta, que tomedes fiadores de los dichos moros fasta en quantía de .XX. mill mrs. a cada uno que parescan ante Nos en la nuestra Corte personalmente del día que la fiaduría les fuere tomada a cada uno dellos fasta .XV. días sobresta rasón de la dicha denunciación que vos fue fecha, como dicho es. E qualquier destos dichos moros que non pareciere ante Nos al dicho plaso, que los fiadores del que non paresciere que peche a Nos de llano los dichos .XX. mill mrs., e el que vaya por hechor de aquella acusación que'l fue fecha. E la dicha fiadura tomada de cada uno dellos, en la manera que dicha es, que los soltedes de la prisión e que les pongades plaso que parescan en la nuestra Corte personalmente ante Nos al dicho plaso que sobredicho es. E este plaso de los .XV. días que sea contado sin los.IX. días de la nuestra Corte e sin los tres días del pregón. E el que fiadores non oviere fasta en la dicha quantía, que lo enbiedes preso e bien 
recabdado a la nuestra Corte a su costa e a su misión, tan bien el que fiso la dicha denunciación como qualquier de los otros. E Nos mandaremos veer la dicha denunciación que fue fecha por que fueron presos los dichos moros e librar como la nuestra merced fuere e falláremos por derecho. E non fagades ende al por ninguna manera, so pena de la nuestra merced e de los cuerpos e de quanto avedes. E de como vos esta nuestra carta fuere mostrada e la cunplierdes, mandamos a qualquier escrivano público que para esto fuere llamado que dé ende al que vos la mostrare testimonio signado con su signo. E non faga ende al so la dicha pena. E porque entendades que esto es mi voluntad, mandamos seellar esta carta con nuestro seello de la poridat. La carta leyda dátgela. Dada en Navamorcuende, .XVII. días de oytobre, era de mill e .CCCLXXVII. annos. Yo, Matheo Ferrandes, la fis escrevir por mandado del Rey».

Las quales leydas, el dicho concejo dixieron que obedecíen las dichas cartas nuestro sennor el Rey, como de su Rey e de su sennor, e dixieron a los dichos moros que les farían mucha onra e mucho plaser. E los dichos jués e alcaldes dixieron que obedecíen las dichas cartas como de su Rey e de su sennor, e dixieron al dicho Ademel que paresciesen los dichos moros ant'ellos tras lunes e que trayesen los fiadores e que gelos recebiríen e que les pornén plasos que pareciesen ante el dicho sennor Rey, segund en la carta del Rey se contiene.

Testigos, Juan Lopes escrivano e Roy Gonçales, fijo de Gonçalo Yannes, e Diago Martines de San Román, e Farach, fijo de Adalit.

[1339/11/02 (martes). Ágreda]

Martes, .II. días de novienbre de la dicha era, en presencia de mí, Pero Ximenes, escrivano público de Ágreda, e de los testigos que aquí son escriptos, en Ágreda, en las casas de Martín Peres, jués de Ágreda, an'el dicho Miguel Peres jués e Martiín Gonçales e Garci Ximenes e Gonçalo de Vera e Garci Sanches e Gil Peres, alcaldes de Ágreda, parecieron Adamel, fijo de don Celín, e de Alí Alfaquí, moros de la morería de Ágreda, mostraron e fisieron ller una carta de nuestro sennor el Rey, fecha en esta guisa:

[inserta de nuevo el mandamiento real de soltura bajo fianza del día 17 de octubre].

La qual leyda, los dichos Adamel e don Alí pidieron a los dichos oficiales e afrontáronles que reciban los fiadores a los dichos don Mahoma e Esmay e Ayn e Çuleyma e Mahoma çapatero, segund el dicho sennor Rey les enbiava mandar.

E dieron por fiadores a Juan Garcés de los Fayos e a Pero Vera, fijo de Ferrant Çapata, e a Roy Ferrandes de don Fernando, e a Valer Garcés, fijo de Ferrant Martines de la Mata, e a Garci Ferrandes, fijo de don Ferrando, e a Gonçalo Martines, fijo de don Gil Peres, arcipreste que fue de Ágreda, e a Garci Ximenes, fijo del dicho Juan Garcés, e a Juan Gonçales, fijo de Juan Gonçales, e a Rodrigo Alfonso, fijo de Alfonso Ferrandes de Quintana, e a Gonçalo Peres, fijo de Domingo Marti- 
nes, e a Juan Garcés, fijo de Ferrant García, e a Pero Ximenes, fijo de Nicolás el çapatero, vesinos de Ágreda, para tener e cunplir todo lo que en la dicha carta del dicho sennor Rey se contiene.

E los dichos Juan Garcés e Pedro Vera e Roy Ferrandes e Valer Garcés e Garci Ferrandes e Gonçalo Martines e Garci Ximenes e Juan Gonçales e Rodrigo Alfonso e Gonçalo Peres e Juan Garcés e Pero Ximnes obligáronse a los dichos oficiales e son fiadores por los dichos don Mahoma Alguasil, fijo de don Hamete, e por Esmay el Bolsero, e por Ayn, fijo de Mahoma d'Ayn, e por Çuleyma de Sancho e por Mahoma çapatero, que los dichos don Mahoma e Esmay e Ayn e Çaleyma e Mahoma que parecerán ante nuestro sennor Rey en la su Corte personalmente de oy día que esta fiadura es tomada cada uno dellos fasta .XV. días, segund en la dicha carta del dicho sennor Rey se contiene, e qualquier de los dichos moros que no paresciere ante el dicho sennor Rey al dicho plaso, como dicho es, que los fiadores del que non paresciere que peche al dicho sennor Rey de llano .XX. mrs. desta moneda que agora corre, que fasen diés dineros el maravedí, por qualquier o qualesquier de los dichos moros que non parescieren an dicho plaso ant'el dicho sennor Rey, como dicho es.

E el moro que non y fuere de los sobredichos que vaya por fechor de la dicha acusación.

E a esto obligaron todos sus bienes muebles e rayses, avidos e por aver, en todos lugares, todos en uno e cada uno dellos por el todo.

E los dichos oficiales dixieron que obedecíen la dicha carta del dicho sennor Rey, como de su Rey e de su sennor, e recibieron la dicha fiadura a los sobredichos para los dichos moros, en la manera que dicha es, e pusieron plaso a los dichos moros que parescan ante nuestro sennor el Rey en la su Corte personalmente al plaso que en la dicha carta se contiene.

Testigos, Blasco Martines e Juan Lopes, escribanos, e don Gonçalo e Gil Peres, andadores, e Mahoma, fijo de Alí.

\section{DOCUMENTO 5}

\section{9/11/05 (viernes). [Ágreda]}

Tres de los alcaldes de fuero ordenan al juez de Ágreda, que tenía preso a su cargo a Adamelque, hijo de Mahoma Alguacil, que le lleve a su presencia para que le pidan sus fiadores y darle plazo para comparecer ante el Rey; los demás implicados ya los habian presentado y hacía dos días que habian marchado hacia la Corte.

Traído a presencia de los alcaldes, dice que no tiene fiadores, que le manden preso a la Corte, pero recusa para ello a uno de los alcaldes. Éstos deciden hablarlo entre ellos para designar a quien lo llevase.

AHMA, Protocolos Antiguos, 02/04, fol. 68v-69r. 
En presencia de mí, Pero Ximenes, escrivano público de Ágreda, e de los testigos que aquí son escriptos, en Ágreda, en las casas de Diego Fernandes, fijo de Gil Peres, Martín Gonçales e Garci Sanches e Gil Peres, alcaldes del dicho lugar, mostraron e fisieron leer un escripto ante Martín Peres jués, fecho en esta guisa:

Miguel Peres jués, ya sabedes en cómo vos tenedes preso por mandado de mí, el dicho Martín Gonçales, a Adamel moro, fijo de don Mahoma el Alguasil. Otrosí, sabedes cómo nuestro sennor el Rey enbió mandar por su carta a los alcaldes e al jués que tomemos buenos fiadores al dicho Adamel e a los otros moros que fueron presos por la dicha denunciación qu'el dicho Adamel fiso, e aquel que no diese fiadores, segund qu'él enbiava mandar, que lo enbiemos preso e bien recabdado a la su Corte a su costa. Et otrosí, sabedes en cómo los dichos moros que an dado fiadores aquellos que cunpe a que parescan ante nuestro sennor el Rey, segund que lo él enbió mandar por su carta. Et ellos son sallidos de la villa de Ágreda dos días a. Et el dicho Adamel non tiene dados los dichos fiadores nin otri por él. Onde vos pedimos e vos requerimos que fagades parecer ante nos al dicho Adamelque e, si quisiere dar fiadores en la manera qu'el dicho sennor Rey enbía mandar por la dicha su carta, recebirgelos hemos e si non que lo nos entregedes e pornemos aquel recabdo en él, porque lo podamos poner en la Corte del dicho sennor Rey al plaso e en la manera que lo enbía mandar por su carta, e en qué día vos fasemos este pedimiento e requerimiento pedimos a Pero Ximenes, escrivano público de Ágreda, que nos dé testimonio signado con su signo.

El qual leydo, los dichos alcaldes pidieron e [intimaron] al dicho Miguel Peres jués que lo quiera así faser e cunplir.

E el dicho Miguel Peres jués dixo que verdat era que por mandado del dicho Martín Gonçales que teníe preso al dicho Adamel e que estava presto e aparejado de le dar e entregar a los dichos Martín Gonçales, Garci Sanches e Gil Peres al dicho Adamel, e ellos que pongan recabdo en el dicho Adamel. E el dicho jués entregógelo luego ante mí, Pero Ximenes escrivano e ante los testigos que aquí serán escriptos.

$\mathrm{E}$ los dichos alcaldes dixieron al dicho Adamel si quiere dar fiadores, segund en la carta del dicho sennor Rey se contiene, que son prestos de gelos recebir, e que'l pornán plaso que paresca personalmente ant'el Rey en la su Corte.

E el dicho Adamel dixo que los fiadores que los non a, pero que requeríe al dicho Miguel Peres jués e a los dichos Garci Sanches e Gil Peres, alcaldes, que lo pongan ant'el dicho sennor Rey, e quanto a Martín Gonçales alcalde que en esta rasón que lo da por sospecha por rasón que dis que lo fiso prender e que manda querellar d'él al dicho sennor Rey, e que en su poder que a recelo de se perder por miedo de muerte; que requeríe a los dichos jués e alcaldes que ellos o qualquier dellos o Gonçalo de Vera o Garci Ximenes alcalde que lo lieven ant'el dicho sennor Rey, segund dicho es, e que está presto de yr luego con ello, e que lo non den en poder del dicho Martín Gonçales; e, si lo non quieren así faser, que protestava contra ellos las costas e la injuria. 
E los dichos Miguel Peres jués e Garci Sanches e Gil Peres alcaldes dixieron que ellos catarán entre sí quién lo lieve e que lo enbiarán ant'el dicho sennor Rey, segund en la su carta se contiene.

Testigos, que fueron presentes a todo lo que dicho es Gonçalo andador e Gil Peres sayón e Mahoma el Ferrero.

\section{DOCUMENTO 6}

\section{9/11/05 (viernes). [Ágreda]}

Los tres alcaldes encomiendan al juez que mantenga preso en su poder a Adamelque hasta tanto que designasen persona que lo llevase a la Corte. El juez acepta.

AHMA, Protocolos Antiguos, 02/04, fol. 69r.

Este día en las dichas casas de Diago Fernandes los dichos Martín Gonçales e Garci Sanches e Gil Peres, alcaldes de Ágreda, dixieron al dicho Miguel Peres jués que, entretanto que ellos catavan entre sí quién levase al dicho Adamel ante nuestro sennor el Rey, que lo toviese preso al dicho Adamel e bien recabdado por nos el Rey las prisiones e lo non dé suelto nin fiado fasta que ellos gelo demanden para enbiarlo al dicho sennor Rey.

E el dicho Miguel Peres jués dixo que le plasíe e recibió al dicho Adamel en su poder.

Testigos, Gonçalo andador e Gil Peres sayón.

\section{DOCUMENTO 7}

\section{9/11/05 (viernes). [Ágreda]}

El juez y dos alcaldes comunican a Gonzalo de Vera, también alcalde de fuero, que debía tomar parte en la deliberación para decidir quién llevaba a Adamelque a la Corte.

Vera niega estar concernido por el mandato real, que decidan ellos. Juez y alcaldes insisten, protestando daños y perjuicios.

AHMA, Protocolos Antiguos, 02/04, fol. 69r-v.

Este día Miguel Peres jués e Martín Gonçales e Garci Sanches e Gil Peres alcaldes dixieron a Gonçalo de Vera alcalde que ya sabíe en cómo nuestro sennor el Rey que enbió mandar por su carta al jués e a los alcaldes que reciban fiadores a los moros e Adamel, fijo de Mahoma el Alguasil, que fiso la denunciación, que paresca ante el dicho sennor Rey, e que ellos que an requerido al dicho Adamel que dé fiadores en la manera que dicha es, e que non gelos quiere dar, disiendo 
que los non puede aver. E requiriéronle que él con ellos que caten entre sí quién lieve al dicho Adamel ant'el dicho sennor, pues que tanbién gelo mandava el Rey a ellos levar el dicho Adamel.

Et el dicho Gonçalo de Vera alcalde dixo que la denunciación que non avíe seydo fecha a él nin la avíe mandado nin [lev]ado él a casa de dicho sennor Rey, nin avíe mandado prender al dicho Adamel nin se avía [estado] en el lugar nin nunca avíe parado este pleito ant'él, pero pues ellos lo teníen preso e lo mandaran prender, que ellos que caten e cunplan lo qu'el dicho sennor Rey enbía mandar a los que la dicha denunciación enbió el dicho sennor Rey.

E los dichos sennores jués e alcaldes dixieron que la dicha denunciación que tanbién fue fecha a él como a ellos e que la carta del dicho sennor así viene a él como a ellos. E, si lo quiere así faser, e si no que protestan contra él dannos e menoscabos que ellos o otri por ellos fisiere por rasón que disíen que non quiere conplir la carta del Rey.

E el dicho Gonçalo de Vera dixo lo de suso.

Testigos, Juan Lopes escrivano e Gil Peres sayón e Gonçalo andador.

\section{DOCUMENTO 8}

\section{9/11/07 (domingo). [Ágreda]}

El juez y los alcaldes de Ágreda, ante el concejo, en cumplimiento de mandamiento real, entregan a Adamelque preso en manos de Garci Sánchez alcalde para que lo presente ante el tribunal real.

AHMA, Protocolos Antiguos, 02/04, fol. 69v.

Seyendo el concejo de Ágreda ayuntados a la puerta de la eglesia de Sant Miguel a concejo repicado, como lo an de uso e de costunbre de se ayuntar, por rasón de una carta de nuestro sennor el Rey, que mostraron Adamel, fijo de Celin e don Alí Alfaquí, moros de la morería de Ágreda, el jués e los alcaldes del dicho lugar, en que les enbiava mandar que tomasen fiadores a don Mahoma, fijo de don Hamete, e a Esmayn el Bolsero e Ayn, fijo de Mahoma d'Ayn, e a Çuleyma de Sancho e a Mahoma çapatero e Adamel, fijo de don Mahoma el Alguasil. E al que no diere fiadores que lo enbiasen preso e bien recabdado ant'el dicho sennor Rey.

E Miguel Peres, jués de Ágreda, e Martín Gonçales e Gil Peres, alcaldes del dicho lugar, movieron en el dicho concejo a Garci Sanches, alcalde del dicho lugar, al dicho Ademel preso en su poder e pusieronle plaso que paresca el dicho Ademel e el dicho Garci Sanches alcalde con él personalmente ant'el dicho sennor Rey al plaso e en la manera qu'el dicho sennor Rey enbiava mandar por su carta, segund en ella se contiene. E obligáronse de pagar la costa con él qu'el dicho Garci Sanches fisiere en levar al dicho Adamel fasta el dicho sennor Rey. 
E el dicho Garci Sanches recibió al dicho Ademel de los dichos jués e alcaldes, e obligose de levar al dicho Ademel, como dicho es, al plaso e en la manera que en la dicha carta del dicho sennor Rey se contiene.

Testigos, Roy Peres, fijo de Gonçalo Yannes, e Gonçalo Garcés de los Fayos e Gonçalo Martines, fijo de Gonçalo Martines. 